\title{
Failure Law and Mechanism of the Rock-Loose Coal Composite Specimen under Combined Loading Rate
}

\author{
Genshui Wu, ${ }^{1}$ Weijian Yu ${ }^{1},{ }^{1,2}$ Ze Liu, ${ }^{1}$ and Zhu Tang ${ }^{1}$ \\ ${ }^{1}$ School of Resource \& Environment and Safety Engineering, Hunan University of Science and Technology, Xiangtan, \\ Hunan 411201, China \\ ${ }^{2}$ Hunan Key Laboratory of Safe Mining Techniques of Coal Mines, Hunan University of Science and Technology, \\ Xiangtan, Hunan 411201, China \\ Correspondence should be addressed to Weijian Yu; ywjlah@163.com
}

Received 14 July 2018; Accepted 28 August 2018; Published 4 October 2018

Academic Editor: Guo-zhong $\mathrm{Hu}$

Copyright (C) 2018 Genshui Wu et al. This is an open access article distributed under the Creative Commons Attribution License, which permits unrestricted use, distribution, and reproduction in any medium, provided the original work is properly cited.

\begin{abstract}
The surrounding rock deformation in the underground mining roadway increases rapidly during excavation and mining disturbance. The semirock and coal roadway, which is formed by the rock and coal composite system, will show different mechanical properties. Therefore, loading rate and anchoring or not are critical to grasp the stability law of the rock-coal combination system under different conditions. The uniaxial mechanical test under the constant loading rate and combined loading rate is carried out in the static loading range $\left(0.01 \sim 10 \mathrm{~mm} \cdot \mathrm{min}^{-1}\right)$ of the rock-loose coal composite specimen (RCCS). The test results show that the rock and loose coal composite specimen without bolt ( $\mathrm{RCB}(0)$ specimen) are abnormal, and the uniaxial compressive strength (UCS) and residual strength (RS) of the specimen do not increase but decrease with the increase of loading rate. In contrast, the UCS of the rock-loose coal composite specimen with the bolt (RCB(1 2) specimen) is consistent with that of the ordinary hard and brittle rock, which increases with the increase of loading rate. To a certain extent, the initial damage and the development of microcracks in loose coal bodies are limited by bolts. Finally, the deformation mechanism and constitutive equation of the rock-loose coal composite system are discussed.
\end{abstract}

\section{Introduction}

Deep rock mass engineering is gradually facing more and more complicated geological conditions. Therefore, complicated engineering problems pose higher challenges to human exploration. The development of underground engineering to the depth has brought about great contradictions with people's common understanding in the past. Deep underground engineering is no longer a single difficult problem but has caused various and multiple impacts. Many scientific problems such as high ground temperature $[1,2]$, high stress $[3,4]$, high gas $[5,6]$, strong impact, long-term creep of rock $[7,8]$, various disturbances, and complex geological structures [9-13] have attracted wide attention of many scholars. The stability problem of the coal-rock combination system refers to two or more types of different rock combination systems under various extreme environments in roadway or chamber engineering. Strictly, the rock-coal combination system is not a whole system. When the rock mechanics difference is too significant, the entire rock-coal mass is disturbed and superposed by various stresses, and the coal and rock experience apparent nonlinear damage. In particular, under certain conditions (e.g., high stress or high gas), the dynamic destruction of coal and gas outburst will occur. Currently, the study on the combination of rock-coal specimens has attracted more and more scholars' attention. For example, Tang et al. [14] used a rock failure process analysis $\left(\mathrm{RFPA}^{2 \mathrm{D}}\right)$, which reveals the evolutionary nature of the fracture phenomenon from microfracture scale to global failure, and they found that the rock interface has self-affine fractal characteristics, and its correlation with fractal dimension is obvious. Zhao et al. [15-18] investigated the cracking and stress-strain behavior and creep properties of rocks and revealed the stress-strain 
curves of the specimens containing two flaws are closely related to the crack development and coalescence process. Mogi [19] proposed the influence of the second principal stress on the fracture mode of rock-coal mass. Wang and Park [20] proposed that the uniaxial compressive strength (UCS) and brittleness coefficient of the specimen can be used to measure the impact capacity when they studied the impact tendency index of rock-coal composite specimen/system (RCCS). The results show that the higher the UCS of the specimen and the greater the brittleness coefficient, the stronger the impact tendency of the rock-coal composite specimen. Zuo et al. [21, 22] did a lot of research on the failure mechanism and mechanical properties of the RCCS and elaborated the mechanical differences between RCCS and coal specimen or rock specimen.

There are only a few reports on the experimental study of RCCS under different test loading strain rates (static range). For example, Huang and Liu [23] studied the RCCSs in 7 orders of magnitude at $0.2 \sim 12.25 \mathrm{kN} / \mathrm{s}$. The results show that with an increase of loading rate, the strain increment of the RCCS in the elastic phase, the plastic phase, and the failure phase gradually increased, and the strain at the peak point rose linearly. Gong et al. [24] carried out four different types of low loading rate $\left(10^{-3} \sim 10^{0} \mathrm{MPa} / \mathrm{s}\right)$ uniaxial compression tests of RCCS. The result shows that with the increase of loading rate, the failure structure of RCCS is transformed from coal part to the whole coal-rock part, and there is an apparent critical loading rate phenomenon.

The above results are based on the analysis or test of the RCCS. More often than not, the impact tendency characteristics of the RCCS are analyzed by the constant loading rate or constant strain rate in the static range. As we know, underground engineering (such as roadway excavation and support) is generally affected by the superposition of dynamic loads and static loads in different degrees and directions due to the influence of in situ stress, structural stress, blasting, working face advancement, various mining methods, and mechanical equipment. Therefore, in response to these problems, Li et al. [25] took the lead in carrying out a series of studies and achieved specific results. Figure 1 shows two typical stress modes of deep engineering rock. $\mathrm{Li}$ et al. $[26,27]$ believe that the mechanical properties of rock such as strength, deformation, failure process, and energy dissipation under combined static and dynamic loads are significantly different from those of traditional statics or dynamics (Figure 1: $P_{\mathrm{s}}$ is static load, and $P_{\mathrm{d}}$ is dynamic load). In contrast, $\mathrm{Li}$ et al. [28] believe that dynamic loads such as underground rockburst are also caused by severe instability of quasi-equilibrium systems. Thus, it is reasonable to use static loading to study the rate effect in the laboratory.

Throughout the work done by researchers in the past, all researchers are focused on the mechanical characteristics of RCCS. However, underground engineering rock mass is often supported by different methods (e.g., bolt, cable, and shotcrete). In order to prevent the rock mass from overall failure due to various disturbance stresses. Therefore, merely testing and analyzing the mechanical properties of rock (RCCS) after loading have limitations with the actual engineering background. Unfortunately, the related research on the rock and coal assemblage with bolt (RCB) has not attracted the attention of more scholars. Therefore, based on the previous research, this paper considered to carry out experimental investigation and deformation mechanism analysis of the rock and loose coal assemblage with the bolt (RCB) with different combinations loading levels (high to low and low to high) within the static strain range.

\section{Division of High and Low Loading Rates under Static Strain Rate}

Generally, according to different loading methods, the whole process of rock loading can be divided into the following corresponding strain rate modes: (1) creep; (2) static; (3) quasi-dynamic; (4) dynamics; and (5) hyper-dynamic. However, the above classification does not provide a definite strain rate range. Based on previous studies, the loading rate range $\left(0.01-10 \mathrm{~mm} \cdot \mathrm{min}^{-1}\right)$ corresponding to the strain rate range $\left(10^{-6} \sim 10^{-3} \cdot \mathrm{s}^{-1}\right)$ determined is divided into quasistatic state, i.e., the low loading rate range. Gong et al. [24] examined the corresponding static range relationship among the controlled loading rate, actual loading rate, and strain rate, as shown in Table 1. After taking the logarithm of the test data, there is a good linear relationship between the actual loading rate and the controlled loading rate and between the strain rate and the calculated actual loading rate. Therefore, in this paper, in the range of the static strain rate, when there is a load level difference in the control load rate, the higher level is the high loading rate, and the lower level is the low loading rate.

\section{Test Preparation}

3.1. Specimen Preparation. The mainly aggregates in the coal body of the RCCS are $150 \mu \mathrm{m}$ diameter coal ash and P42.5 Portland cement, with a mass ratio of $2: 3$. Meanwhile, a loose coal-rock mass is made by adding $30 \%$ hydrogen peroxide $\left(\mathrm{H}_{2} \mathrm{O}_{2}\right)$. The main aggregate of the rock part is $75 \mu \mathrm{m}$ diameter river sand and Portland cement, with a mass ratio of 2:3 (as shown in Figure 2). The coal ash and river sand were screened with 100- and 200-mesh sieves, respectively.

The loose coal and rock mass were poured into the standard mold by volume ratio $1: 1$, and the RCCS diameter is $50 \mathrm{~mm}$, and the height is $100 \mathrm{~mm}$. To better reflect the contact characteristics of multiple strata, the contact surface between coal and rock is formed by natural cementation. Before creating the test specimen, the piece is first dried in a constant temperature drying oven for 3 hours and then demolded. The samples were then naturally cured by constant temperature curing box, and the molded specimens are shown in Figure 3(b). Horizontal anchor holes with a diameter of $4 \mathrm{~mm}$ are drilled in the loose coal body by using a drilling rig, specifically, single anchor and double anchor anchoring methods. The specimen is anchored with the fullthread bolt, and the specific parameters are diameter $4 \mathrm{~mm}$, length $65 \mathrm{~mm}$, and anchor plate at the end, as shown in Figures 3(c) and 3(d). In this experiment, we mainly carry 


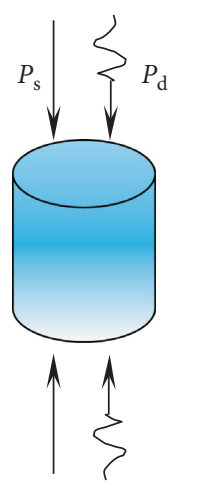

(a)

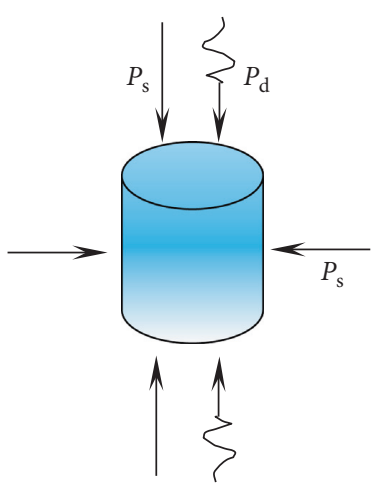

(b)

Figure 1: Two typical stress modes of deep engineering rock [25]: (a) one-dimensional force; (b) multidimensional force.

TABLE 1: Relationship between three loading rates in the static range [24].

\begin{tabular}{lcccc}
\hline $\begin{array}{l}\text { Sample } \\
\text { number }\end{array}$ & $\begin{array}{c}\text { Load } \\
\text { magnitude }\end{array}$ & $\begin{array}{c}\text { Control } \\
\text { loading rate } \\
\left(\mathrm{mm} \cdot \mathrm{min}^{-1}\right)\end{array}$ & $\begin{array}{c}\text { Actual } \\
\text { loading rate } \\
\left(\mathrm{MPa} \cdot \mathrm{s}^{-1}\right)\end{array}$ & $\begin{array}{c}\text { Strain } \\
\text { rate }\left(\mathrm{s}^{-1}\right)\end{array}$ \\
\hline CR1 & I & 0.01 & $6.10 \times 10^{-3}$ & $3.22 \times 10^{-6}$ \\
CR2 & - & - & $5.91 \times 10^{-3}$ & $3.29 \times 10^{-6}$ \\
CR3 & II & 0.1 & $6.26 \times 10^{-2}$ & $3.29 \times 10^{-5}$ \\
CR5 & - & - & $6.59 \times 10^{-2}$ & $3.21 \times 10^{-5}$ \\
CR6 & III & 1 & $7.35 \times 10^{-1}$ & $3.48 \times 10^{-4}$ \\
CR7 & - & - & $3.93 \times 10^{-1}$ & $1.62 \times 10^{-4}$ \\
CR8 & IV & 10 & $7.81 \times 10^{0}$ & $3.48 \times 10^{-3}$ \\
CR9 & - & - & $8.02 \times 10^{0}$ & $3.45 \times 10^{-3}$ \\
\hline
\end{tabular}

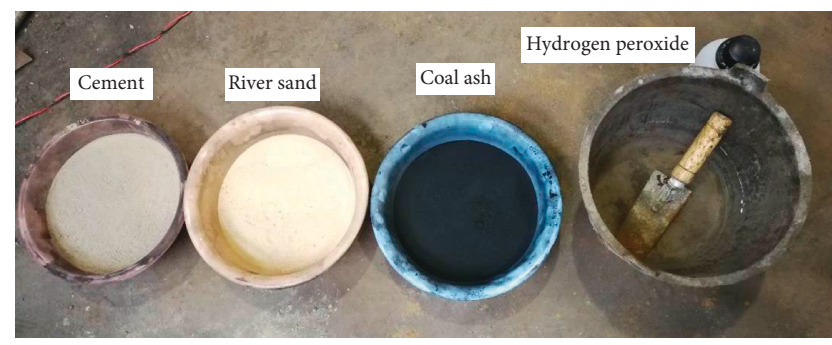

FIGURE 2: Rock-loose coal composite specimen (RCCS) prepared material.

out the analysis of RCB specimen under the condition of combined loading rate, in which coal specimens, rock specimens, and rock and loose coal composite specimens without bolts are taken as the control group for analysis.

3.2. Test Equipment and Methods. The RCCS was carried out on the rock mechanics test (RMT-150C). Two loading rates of $1.2 \mathrm{~mm} / \mathrm{min}$ and $0.3 \mathrm{~mm} / \mathrm{min}$ were set in this experiment, respectively. The differential rate of the two rates was one order of magnitude, representing the high loading rate and low loading rate in the static strain range. The test is divided into the following two ways: (1) set the constant loading rates of $0.3 \mathrm{~mm} / \mathrm{min}$ and $1.2 \mathrm{~mm} / \mathrm{min}$ for the failed test of the rockloose coal composite specimen without bolt, i.e., $\mathrm{RCB}(0)$, the numbers in parentheses represent the number of horizontal bolts; (2) RCB(1 2): set two-stage loading steps in the whole process of test loading, high and low combined loading rates $(1.2 \mathrm{~mm} / \mathrm{min} \longrightarrow 0.3 \mathrm{~mm} / \mathrm{min} ; 0.3 \mathrm{~mm} / \mathrm{min} \longrightarrow 1.2 \mathrm{~mm} / \mathrm{min})$ for the uniaxial failure test. Specifically, when the loading rate reaches $50 \% \sim 60 \% \sigma_{\mathrm{c}}$ of the uniaxial compressive strength (UCS) of the $\mathrm{RCB}(1 \sim 2)$ specimen, it changes a loading order until the specimen failure. The stress path of the test loading is as shown in Figure 4.

\section{Analysis of Test Results}

4.1. Constant Loading Rate. Under a constant loading rate of $0.3 \mathrm{~mm} / \mathrm{min}$, the mean uniaxial compressive strength (MUCS) of the whole rock specimen is $10.41 \mathrm{MPa}$. The coal body is loose inside and contains many defects. Therefore, the MUCS of coal specimens is $2.10 \mathrm{MPa}$, which is entirely different from coal and rock specimen. Figure 5 shows the stress-strain curves of the $\mathrm{RCB}(0)$ specimen at a constant low rate of $0.3 \mathrm{~mm} / \mathrm{min}$ and a constant high rate of $1.2 \mathrm{~mm} / \mathrm{min}$. Generally, the UCS of intact hard and brittle rocks increases with the increase of loading rate $[29,30]$. However, after raising the constant loading rate by one order of magnitude (i.e., from low loading rate to high loading rate), the test results of $\mathrm{RCB}(0)$ specimen were abnormal. The UCS and residual strength (RS) of the specimen did not increase but decreased with the loading rate (about $1 \mathrm{MPa}$ ).

This unusual phenomenon can be well explained by using the critical value effect of the loading rate: loose coal has limited carrying capacity compared with hard and brittle rocks, and its mechanical properties are entirely different from those of conventional intact and brittle rocks. Li et al. [31] believes that the loading rate of rocks with more internal defects (such as $\mathrm{RCB}(0)$ specimen) has a critical value (as shown in Figure 6). When loading rate is less than this critical value, smaller defects are activated inside the specimen. Since the stress concentration level at the defect is positively correlated with the loading rate, the larger the loading rate, the easier the crack will expand and penetrate. Therefore, with the increase of the loading rate, the UCS of the specimen will gradually decrease instead. Thus, the loose coal-rock composite system also has a critical loading rate effect, and the loading rate of $0.3 \mathrm{~mm} / \mathrm{min}$ to $1.2 \mathrm{~mm} / \mathrm{min}$ 


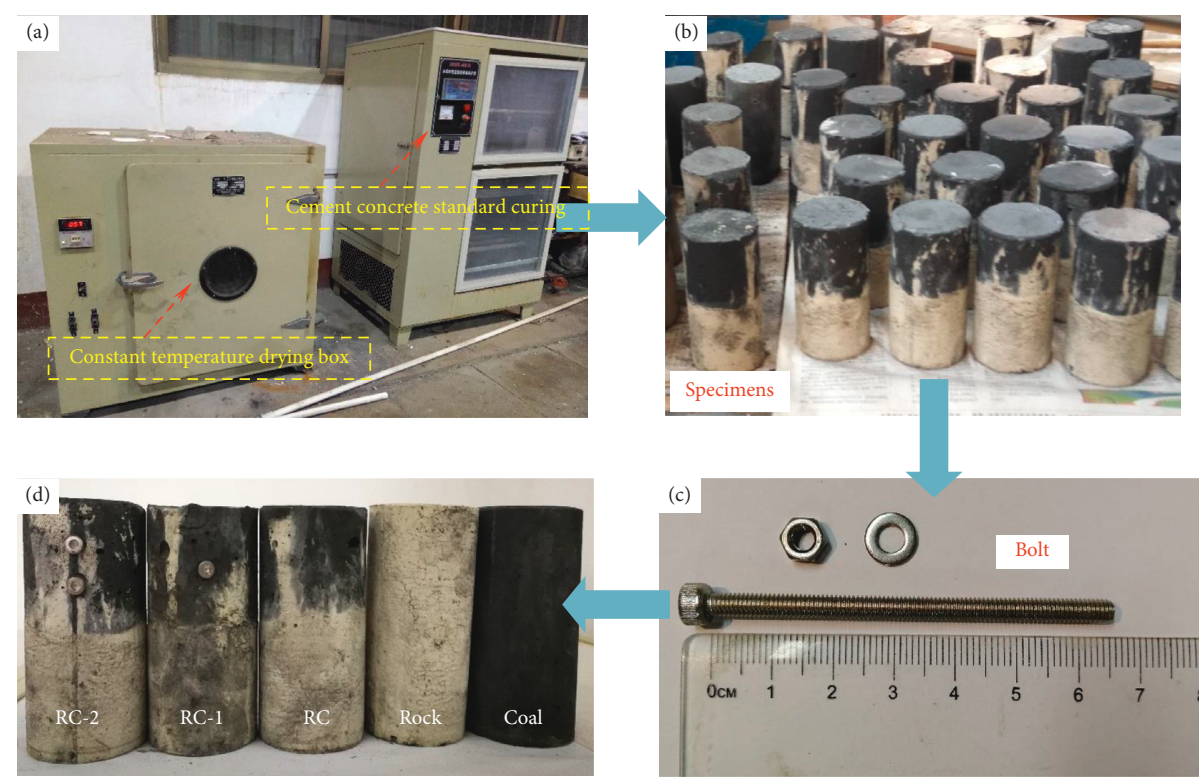

FIGURE 3: Specimen curing formation: (a) maintenance equipment; (b) specimens; (c) bolt; and (d) molding specimens.

belongs to the stage before the critical value changes. Because the rock part of the coal-rock composite specimen is better than the integrity of the coal part and the loose coal is a weak part, its overall mechanical characteristics are consistent with those of the loose coal.

4.2. Combined Loading Rate. Figure 7 shows the stressstrain curves of $\mathrm{RCB}(1)$ and $\mathrm{RCB}(2)$ specimens in the whole process of combined loading rates. The UCS of $\mathrm{RCB}(1)$ and $\mathrm{RCB}(2)$ specimens has been improved due to the reinforcement effect of bolts $(0.337-1.252 \mathrm{MPa}$, Figures 7(a) and 7(b)). The UCS of RCB(1) and RCB(2) specimens under the loading rate from low to high $(0.3 \mathrm{~mm} / \mathrm{min} \longrightarrow 1.2 \mathrm{~mm} / \mathrm{min})$ is higher than that of high to low loading rate $(1.2 \mathrm{~mm} / \mathrm{min} \longrightarrow 0.3 \mathrm{~mm} / \mathrm{min})$. Therefore, the $\mathrm{RCB}(1-2)$ specimen is mainly affected by the loading rate control in the latter half of the process. In other words, the UCS of the RCB(1-2) specimen increases with the increase of the loading rate near failure within the appropriate strain rate. It is found that in the first stage of loading in the combined loading rate (Figures $7(\mathrm{a})$ and $7(\mathrm{~b})$ ), $\mathrm{RCB}(1)$ and $\mathrm{RCB}(2)$ specimens showed large fluctuation under low loading $(0.3 \mathrm{~mm} / \mathrm{min})$, and in contrast, the specimens showed a good linear elastic trend under high loading rate $(1.2 \mathrm{~mm} / \mathrm{min})$. Due to the long loading time with low loading rate, the internal defects of loose coal body yield obviously, but it is not damaged, and the cumulative damage of coal body is higher than that of high loading rate. The UCS of the specimen is changed by way of bolting methods, and the UCS of the RCB (2) specimen is the largest (6.162 MPa), the UCS of the RCB(1) specimen is the second $(3.046 \mathrm{MPa})$, and the UCS of the specimen without bolting is the smallest $(2.180 \mathrm{MPa})$.

There are differences between the mechanical characteristics of the $\mathrm{RCB}(0)$ specimen and the mechanical characteristics of the RCB(1 2) specimen. As we know, loose coal is a structural medium containing various defects; due to the reinforcement of loose coal by bolts and the lateral limitation on the deformation of coal, the mechanical differences between coal and rock mass are reduced. Then, the bearing capacity is improved. To a certain extent, the initial damage inside loose coal and the evolution and development of microcracks are limited by bolts (Figure 8 ). With the increase of loading rate, the development time of fissures in the coal body decreases, the damage degree of the specimen decreases, and the strength continuously increases. Therefore, the UCS of the RCB(1 2) specimen is consistent with that of the hard and brittle rock, and UCS increases with the increase of loading rate.

4.3. Failure Law. Figure 9 shows the failure law of the RCB (0) specimen under the constant loading rate. The failure of the rock-coal composite specimen is concentrated in the loose coal part; destruction is mainly caused by loose fracture; and there is no apparent shear zone. At the interface between coal and rock, a small range of sliding damage occurred, and finally, the loose coal body cracked, and the whole specimen lost its stable bearing capacity.

Figure 10 illustrates the failure law of the $\mathrm{RCB}(1 \sim 2)$ specimen under combined loading rate. Because bolt changes the mechanical properties of loose coal, the mechanical difference between coal and rock is reduced, and the overall bearing capacity of rock-loose coal composite specimen is also improved. When the specimen is damaged, the development of microcracks is due to the bolt where it does not randomly distribute, but first occurs at the end of the bolt and stress concentration, as shown in Figure 8. Finally, the cracks gradually penetrate. Therefore, the bolt can improve the distribution of the fracture development of loose coal and adjust the integrity of the specimen. Compared with the $\mathrm{RCB}(0)$ specimen, the $\mathrm{RCB}(1 \sim 2)$ specimen has formed a typical failure mode of overall shear splitting failure. 


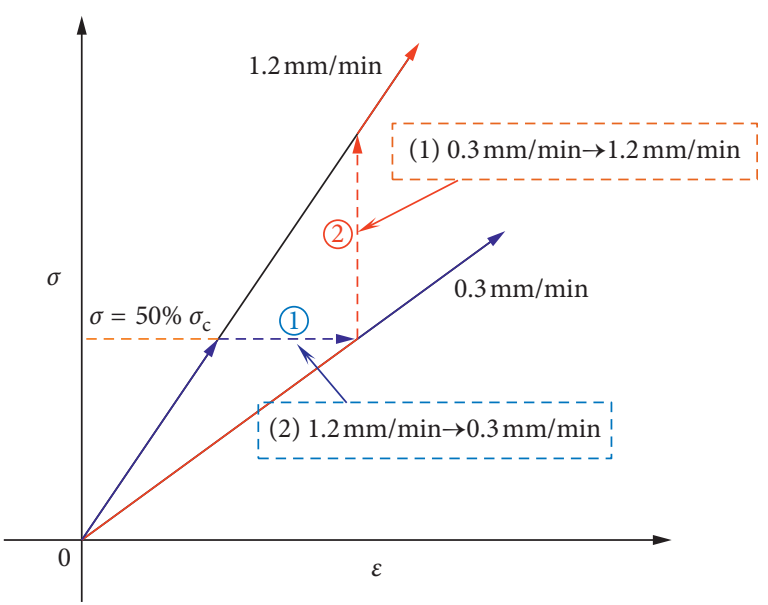

Figure 4: Stress loading path.

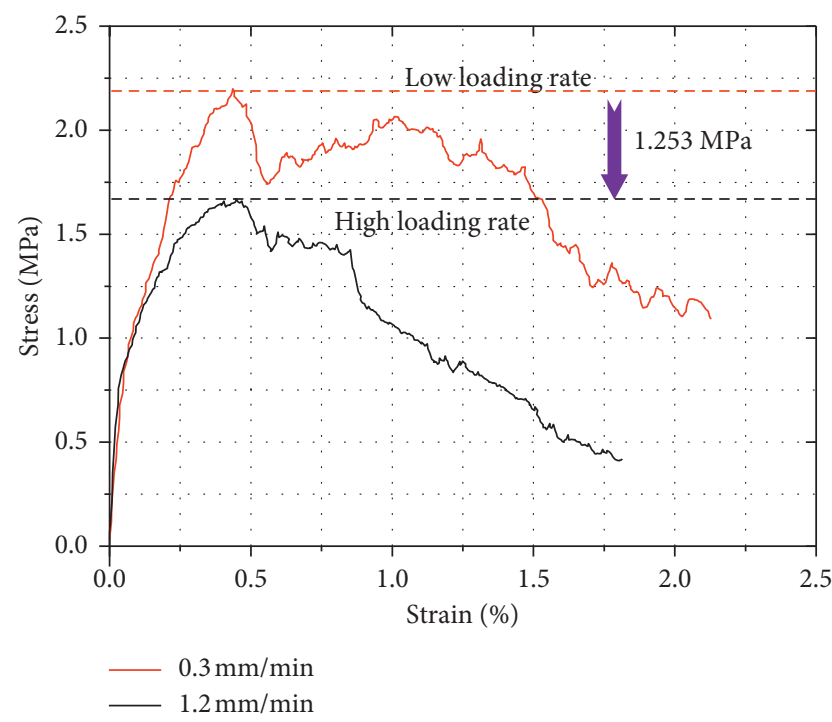

FIGURE 5: Stress-strain curves of the $\mathrm{RCB}(0)$ specimen under constant loading rate.

\section{Discussion on Deformation Mechanism and Constitutive Equation of Rock-Loose Coal Composite System (RCCS)}

Based on a large number of actual rock mass projects, Sun and Sun [32] believe that rock deformation is caused by the joint action of rock mass material deformation and rock mass structural element deformation, which can be expressed as follows:

$$
U=U_{\mathrm{m}}+U_{\mathrm{s}}
$$

where $U$ is the rock deformation, $U_{\mathrm{m}}$ is the rock mass material deformation, and $U_{\mathrm{s}}$ is the rock mass structural deformation.

Therefore, based on the volume deformation and the structural elements deformation of rock material, Sun and Sun [32] suggested that the deformation mechanism of rock be expressed by deformation mechanism elements and abstracted it into 8 kinds of deformation mechanism

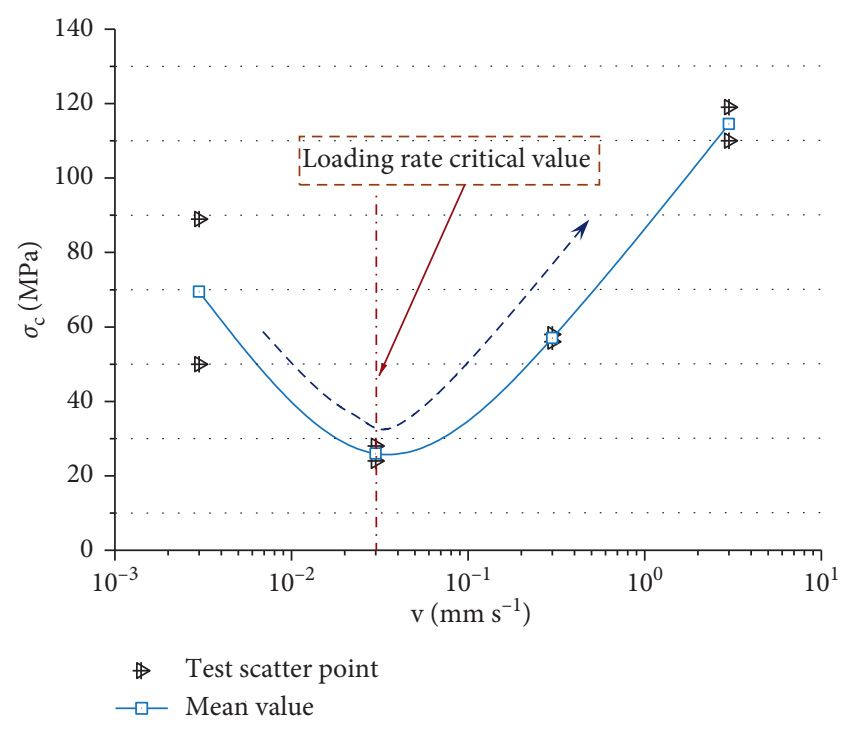

FIGURE 6: Change curves of mudstone peak strength with loading rates [27].

elements, namely, (1) elastic deformation mechanism elements of rock mass material unit body expansion and contraction; (2) rock material unit expansion and shrinkage adhesive deformation element; (3) rock mass material unit closed deformation of structural plane; (4) rock mass material unit staggered deformation of the structural plane; (5) structural plane sliding deformation mechanism elements of rock mass structural elements; (6) the rolling deformation mechanism of the fractured rock mass structure; (7) weak interlayer extrusion deformation mechanism elements of rock mass structural elements; and (8) bending deformation mechanism elements of plate-shaped structural elements of rock mass. Therefore, the rock-loose coal composite system without bolt can be seen as a horizontally layered viscoelastic model. Figure 11 shows the deformation mechanism of the rock-loose coal composite system without bolt.

Based on the geomechanical model of the rock-loose coal composite system, one-dimensional deformation constitutive equation can be obtained:

$$
\dot{\varepsilon}=\frac{1}{E_{\mathrm{b}}}+\frac{1}{E_{\mathrm{j}}}\left(\varepsilon_{\mathrm{j} 0}-\varepsilon_{\mathrm{j}}\right)+\frac{\sigma}{\eta},
$$

where $\dot{\varepsilon}$ is strain rate, $E_{\mathrm{b}}$ is the rock structure elastic modulus, $E_{\mathrm{j}}$ is elastic modulus of structure surface, $\varepsilon_{\mathrm{j} 0}$ is initial structural plane strain, $\varepsilon_{\mathrm{j}}$ is the structural plane strain, $\sigma$ is the stress, and $\eta$ is the viscosity coefficient.

The constitutive equation under constant strain rate $\dot{\varepsilon}_{\mathrm{a}}$ control is given as follows:

$$
\sigma=\frac{\varepsilon_{\mathrm{a}} \eta\left[1-\exp \left(-E_{\mathrm{c}} / \varepsilon_{\mathrm{a}}\right)\right]\left(\eta_{\mathrm{r}}+E_{\mathrm{r}} \varepsilon / \varepsilon_{\mathrm{a}}\right)}{\eta\left[1-\exp \left(-E_{\mathrm{c}} / \varepsilon_{\mathrm{a}} \eta_{\mathrm{c}}\right)\right]+\eta_{\mathrm{r}}+E_{\mathrm{r}} \varepsilon / \varepsilon_{\mathrm{a}}},
$$

where $E_{\mathrm{c}}$ and $E_{\mathrm{r}}$ are the elastic modulus of loose coal and rock, respectively, $\eta_{\mathrm{c}}$ and $\eta_{\mathrm{r}}$ are the viscosity coefficients of loose coal and rock, respectively.

After the loose coal part is anchored, the mechanical homogenization of the rock-loose coal composite system 


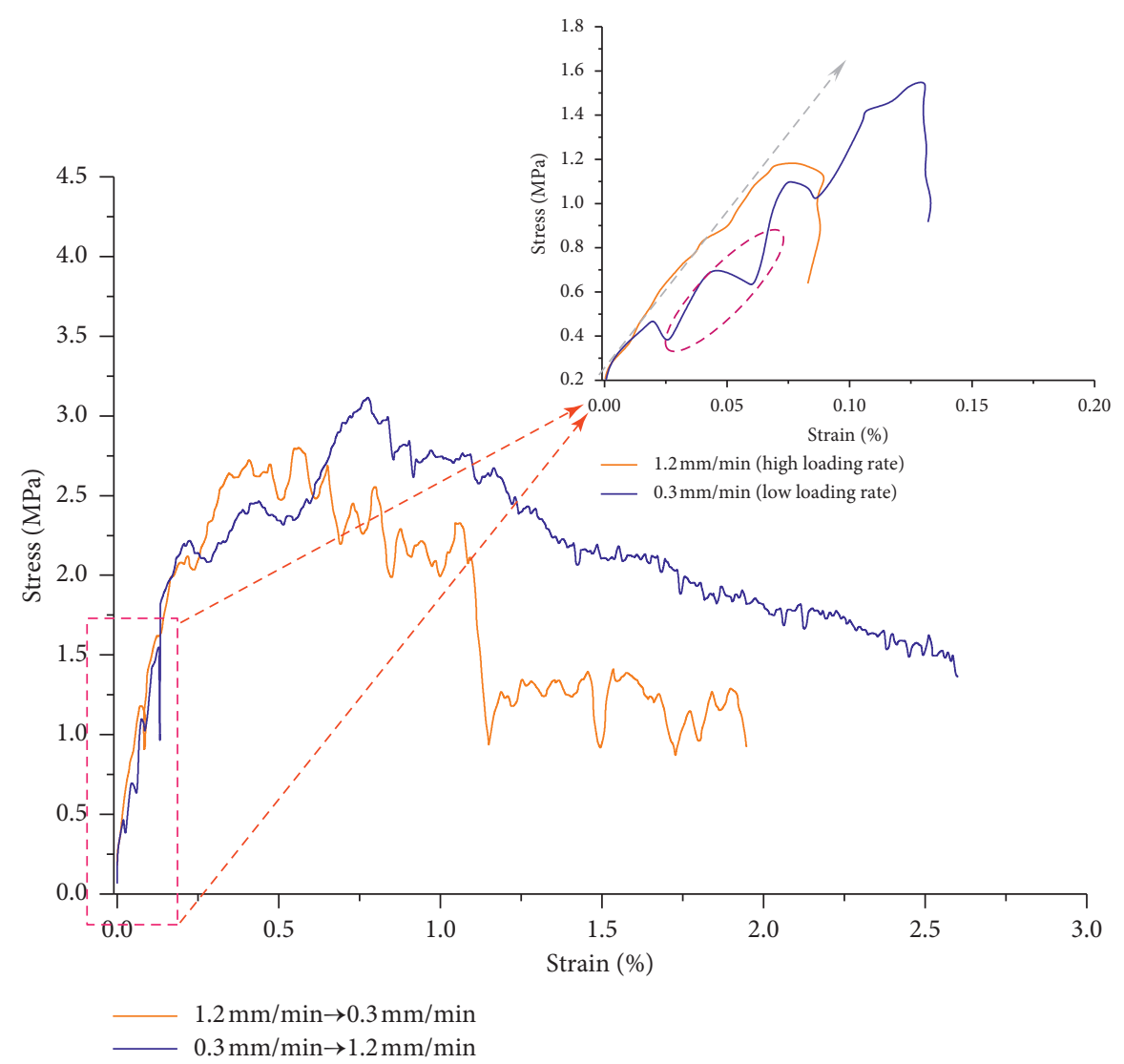

(a)

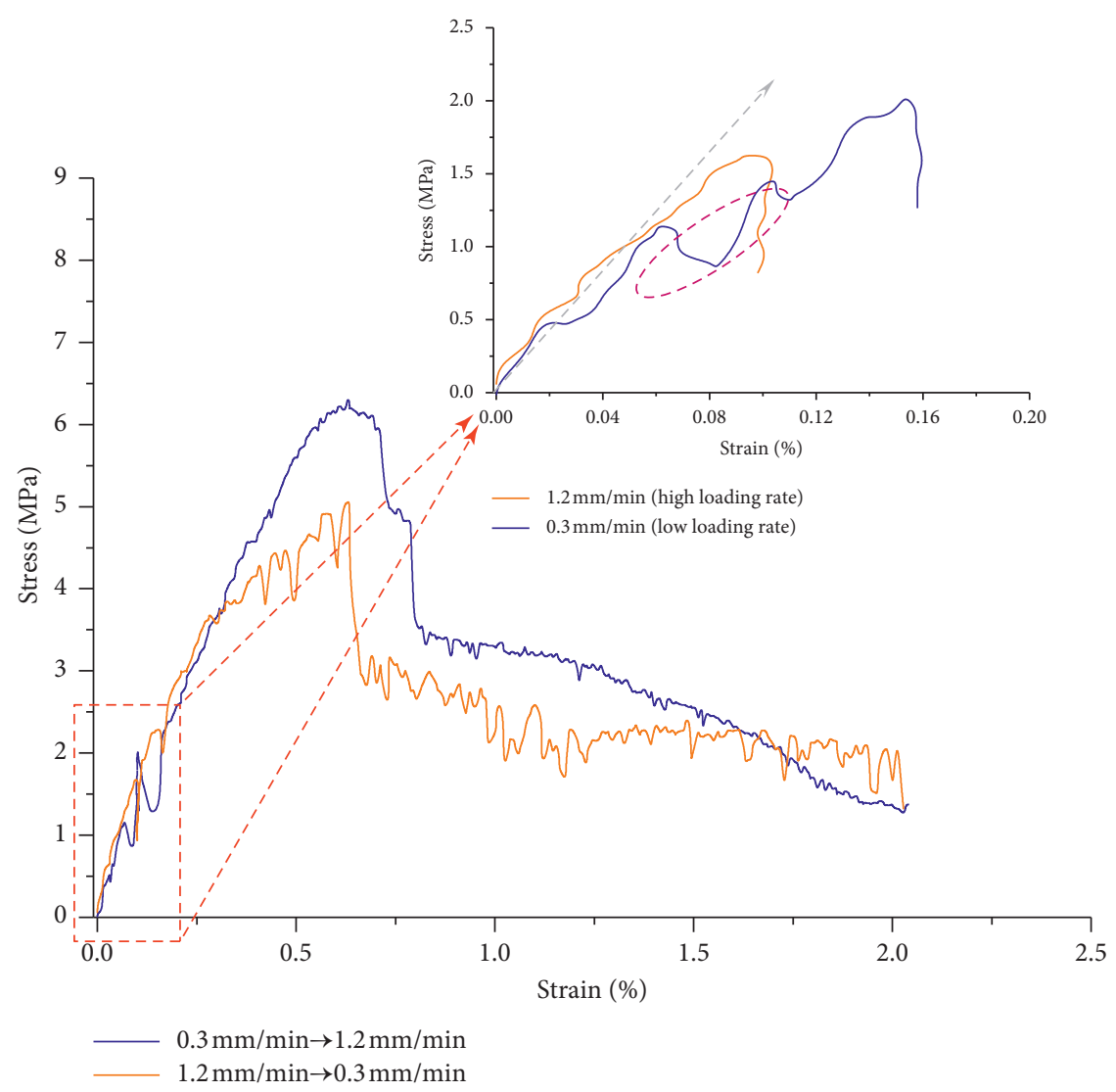

(b)

FIgURE 7: Stress-strain curves of the $\mathrm{RCB}(1 \sim 2)$ specimen under combined loading rate: (a) RCB(1) specimen; (b) RCB(2) specimen. 


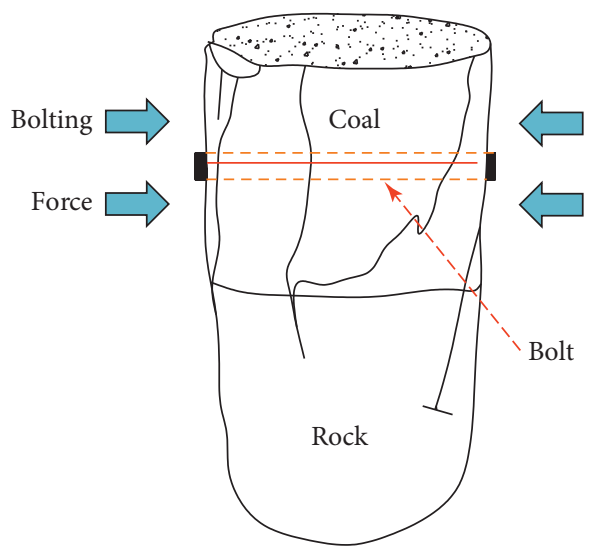

(a)

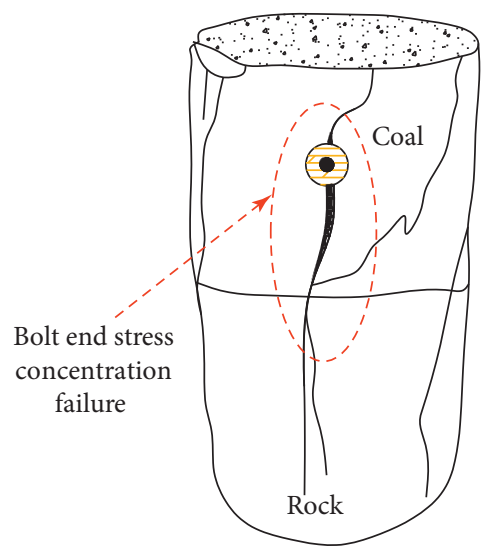

(b)

Figure 8: Rock bolt restriction specimen failure sketch map.

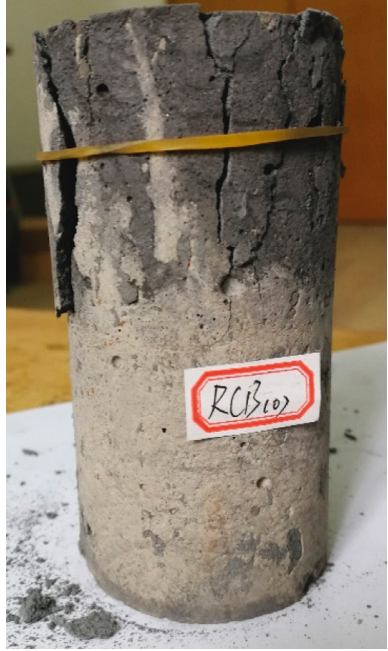

(a)

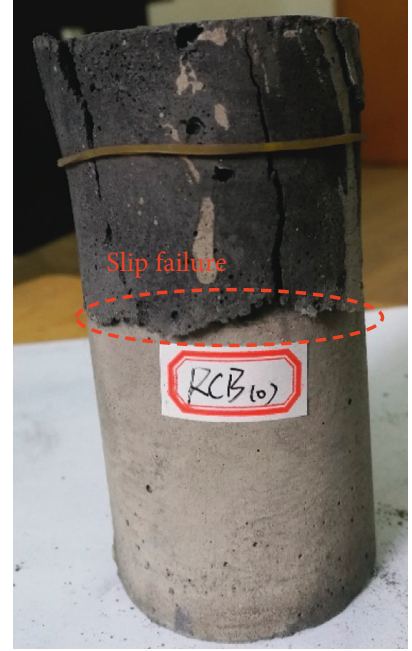

(b)

Figure 9: The failure law of the $\mathrm{RCB}(0)$ specimen under the constant loading rate.

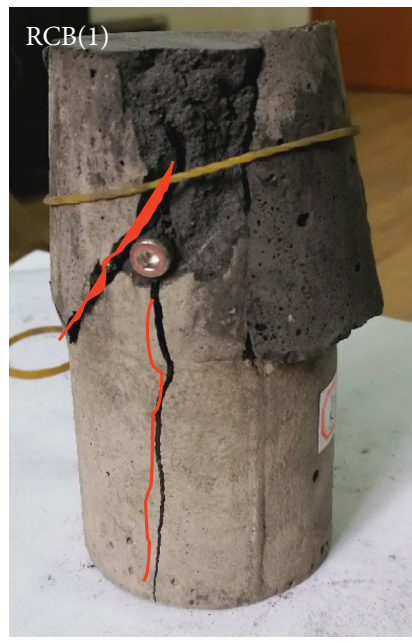

(a)

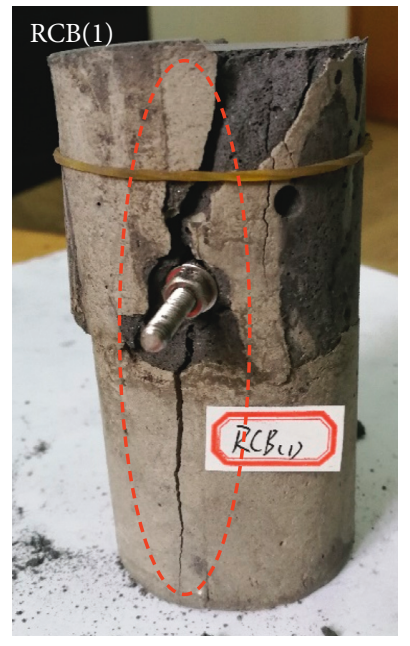

(b)

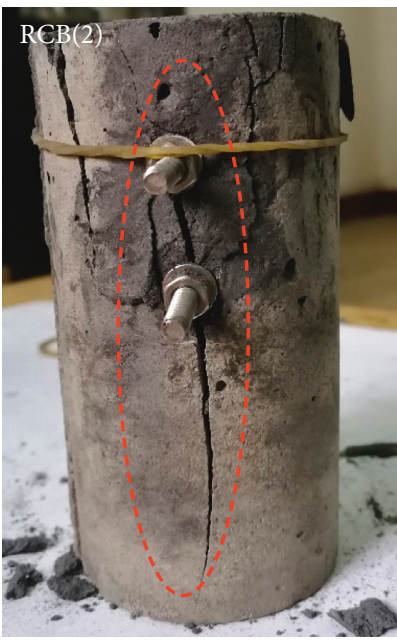

(c)

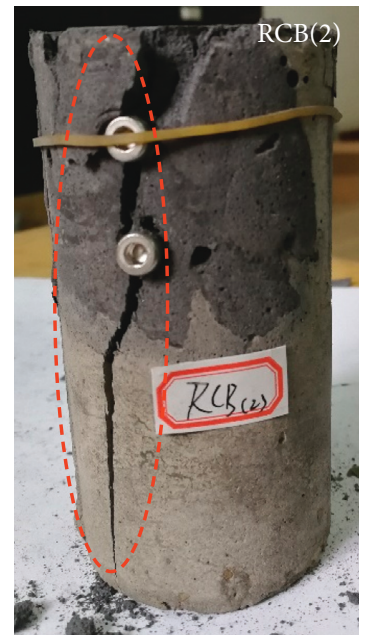

(d)

Figure 10: The failure law of the $\mathrm{RCB}(1 \sim 2)$ specimen under combined loading rate. 


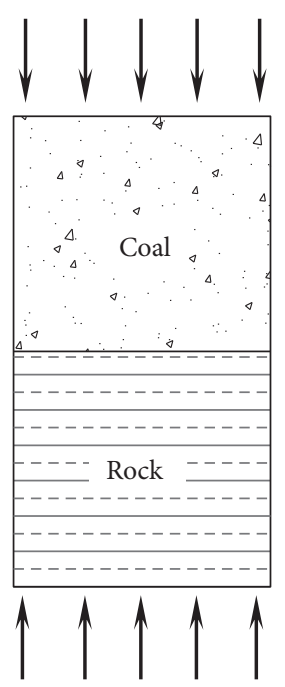

(a)

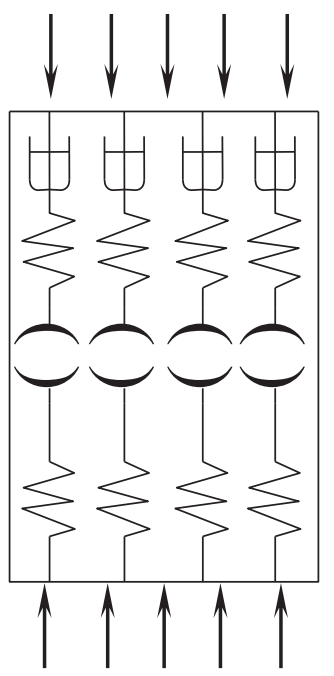

(b)

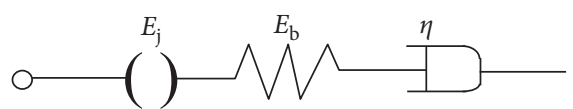

(c)

FIgURE 11: The deformation mechanism of the rock-loose coal composite system without bolt: (a) geological model of RCB(0); (b) physical model of $\mathrm{RCB}(0)$; (c) deformation mechanism.

is improved. Thus, it can be regarded as a common homogeneous elastic fracture rock mass model, as shown in Figure 12.

Therefore, the deformation constitutive equation of the rock-loose coal composite system with bolt can be obtained:

$$
\varepsilon=\frac{\sigma}{E_{\mathrm{b}}}+\varepsilon_{\mathrm{j} 0}\left[1-\exp \left(-\frac{\sigma}{E_{\mathrm{j}}}\right)\right] .
$$

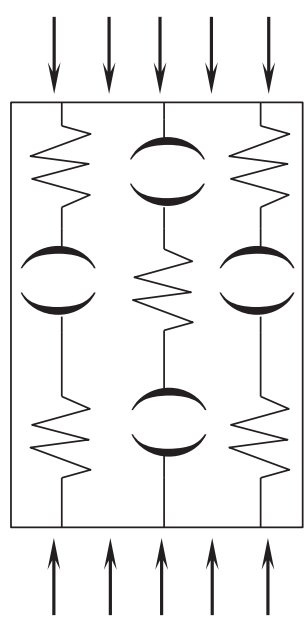

(a)

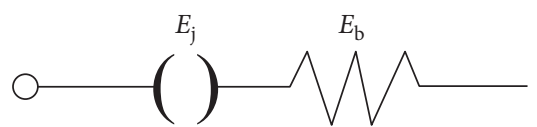

(b)

FIgURE 12: The deformation mechanism of the rock-loose coal composite system with bolt: (a) physical model of RCB(1 2); (b) deformation mechanism.

\section{Conclusions}

In this paper, laboratory tests and theoretical analysis were used to analyze the failure law and mechanism of the rockloose coal composite specimen/system (RCCS). The following conclusions are drawn:

(1) After increasing the constant loading rate by one order of magnitude (i.e., from low loading rate to high loading rate), the test results of $\mathrm{RCB}(0)$ specimen were abnormal. The UCS and RS of the specimen did not increase but decreased with the loading rate.

(2) The UCS of the RCB(1 2) specimen is consistent with the hard and brittle rock, i.e., the UCS increases with the increase of loading rate. Under combined loading rate, with the increase of loading rate, the development time of fissures in the coal body decreases, thus the damage degree of specimen decreases, and the strength continuously increases.

(3) Rocks with more internal defects (such as $\mathrm{RCB}(0)$ specimen) has a critical value in the loading rate. When loading rate is less than of this critical value, smaller defects are activated inside the specimen. The larger the loading rate, the easier the crack will expand and penetrate. Therefore, with the increase of the loading rate, the UCS of the specimen will gradually decrease instead. Similarly, when the loading rate is less than the critical value, the UCS of the specimen increases with the increase of loading rate.

(4) The rock-loose coal composite system without bolt can be seen as a horizontally layered viscoelastic model. After the loose coal part is anchored, the mechanical homogenization of the rock-loose coal composite system is improved. Thus, it can be 
regarded as a common homogeneous elastic fracture rock mass model.

\section{Data Availability}

The data used to support the findings of this study are available from the corresponding author upon request.

\section{Conflicts of Interest}

The authors declare that they have no conflicts of interest.

\section{Acknowledgments}

This study was supported by the National Natural Science Foundation of China (51574122, 51434006, and 51774130), and Hunan Provincial Innovation Foundation for Postgraduate (CX2017B647). The financial supports are greatly appreciated.

\section{References}

[1] M. Mohamadi and R. G. Wan, "Strength and post-peak response of Colorado shale at high pressure and temperature," International Journal of Rock Mechanics \& Mining Sciences, vol. 84, pp. 34-46, 2016.

[2] J. Kodama, T. Goto, Y. Fujii, and P. Hagan, "The effects of water content, temperature and loading rate on strength and failure process of frozen rocks," International Journal of Rock Mechanics \& Mining Sciences, vol. 62, pp. 1-13, 2013.

[3] C. C. Li, "Field observations of rock bolts in high stress rock masses," Rock Mechanics \& Rock Engineering, vol. 43, no. 4, pp. 491-496, 2010.

[4] W. J. Yu and F. F. Liu, "Stability of close chambers surrounding rock in deep and comprehensive control technology," Advances in Civil Engineering, vol. 2018, Article ID 6275941, 18 pages, 2018.

[5] M. B. Wold, L. D. Connell, and S. K. Choi, “The role of spatial variability in coal seam parameters on gas outburst behaviour during coal mining," International Journal of Coal Geology, vol. 75 , no. 1, pp. 1-14, 2008.

[6] C. J. Bibler, J. S. Marshall, and R. C. Pilcher, "Status of worldwide coal mine methane emissions and use," International Journal of Coal Geology, vol. 35, no. 1-4, pp. 283-310, 1998.

[7] Y. L. Zhao, L. Y. Zhang, W. J. Wang, W. Wan, and W. H. Ma, "Separation of elastoviscoplastic strains of rock and a nonlinear creep model," International Journal of Geomechanics, vol. 18, no. 1, article 04017129, 2018.

[8] Y. L. Zhao, L. Y. Zhang, W. J. Wang, J. Z. Tang, H. Lin, and W. Wan, "Transient pulse test and morphological analysis of single rock fractures," International Journal of Rock Mechanics \& Mining Sciences, vol. 91, no. 1, pp. 139-154, 2017.

[9] T. B. Zhao, W. Y. Guo, Y. L. Tan, Y. C. Yin, L. S. Cai, and J. F. Pan, "Case studies of rock bursts under complicated geological conditions during multi-seam mining at a depth of 800 m," Rock Mechanics \& Rock Engineering, vol. 51, no. 5, pp. 1-26, 2018.

[10] W. J. Yu, W. J. Wang, G. S. Wu, X. Y. Yu, and W. Q. Peng, "Three zones and support technique for large section incline shaft crossing goaf," Geotechnical \& Geological Engineering, vol. 35, no. 5, pp. 1921-1931, 2017.
[11] W. J. Yu, W. J. Wang, X. Y. Chen, and S. H. Du, "Field investigations of high-stress soft surrounding rocks and deformation control," Journal of Rock Mechanics and Geotechnical Engineering, vol. 7, no. 4, pp. 421-433, 2015.

[12] W. J. Yu, S. H. Zhai, and Q. Gao, "Stability evaluation indexes of deep stope pillar and roadway surrounding rock," Disaster Advances, vol. 5, no. 4, pp. 120-126, 2012.

[13] W. J. Yu, G. S. Wu, and B. F. An, "Investigations of support failure and combined support for soft and fractured coal-rock tunnel in tectonic belt," Geotechnical \& Geological Engineering, pp. 1-19, 2018.

[14] Z. H. Li, E. Y. Wang, J. C. Ou, and Z. T. Liu, "Hazard evaluation of coal and gas outbursts in a coal-mine roadway based on logistic regression model," International Journal of Rock Mechanics \& Mining Sciences, vol. 80, pp. 185-195, 2015.

[15] J. C. Wang, F. X. Jiang, X. J. Meng, X. Y. Wang, S. T. Zhu, and Y. Feng, "Mechanism of rock burst occurrence in specially thick coal seam with rock parting," Rock Mechanics \& Rock Engineering, vol. 49, no. 5, pp. 1953-1965, 2016.

[16] C. A. Tang, W. T. Yang, Y. F. Fu, and X. H. Xu, "A new approach to numerical method of modelling geological processes and rock engineering problems-continuum to discontinuum and linearity to nonlinearity," Engineering Geology, vol. 49, no. 3-4, pp. 207-214, 1998.

[17] Y. L. Zhao, Y. X. Wang, W. J. Wang, W. Wan, and J. Z. Tang, "Modeling of non-linear rheological behavior of hard rock using triaxial rheological experiment," International Journal of Rock Mechanics \& Mining Sciences, vol. 93, no. 3, pp. 66-75, 2017.

[18] Y. L. Zhao, L. Y. Zhang, W. J. Wang, C. Z. Pu, W. Wan, and J. Z. Tang, "Cracking and stress-strain behavior of rock-like material containing two flaws under uniaxial compression," Rock Mechanics and Rock Engineering, vol. 49, no. 7, pp. 2665-2687, 2016.

[19] K. Mogi, Experimental Rock Mechanics, Taylor \& Francis, Didcot, UK, 2006.

[20] J. A. Wang and H. D. Park, "Comprehensive prediction of rockburst based on analysis of strain energy in rocks," Tunnelling \& Underground Space Technology, vol. 16, no. 1, pp. 49-57, 2001.

[21] J. P. Zuo, H. P. Xie, B. B. Meng, and J. F. Liu, "Experimental research on loading-unloading behavior of coal-rock combination bodies at different stress levels," Rock and Soil Mechanics, vol. 32, no. 5, pp. 1287-1296, 2011.

[22] J. P. Zuo, Z. F. Wang, H. W. Zhou, J. L. Pei, and J. F. Liu, "Failure behavior of a rock-coal-rock combined body with a weak coal interlayer," International Journal of Mining Science and Technology, vol. 23, no. 6, pp. 907-912, 2013.

[23] B. X. Huang and J. Liu, "The effect of loading rate on the behavior of samples composed of coal and rock," International Journal of Rock Mechanics \& Mining Sciences, vol. 61, no. 10, pp. 23-30, 2013.

[24] F. Q. Gong, Y. E. Hao, and Y. Luo, "Rate effect on the burst tendency of coal-rock combined body under low loading rate range," Journal of China Coal Society, vol. 42, no. 11, pp. 2852-5860, 2017.

[25] X. B. Li, Z. L. Zhou, Z. Y. Ye et al., "Study of rock mechanical characteristics under coupled static and dynamic loads," Chinese Journal of Rock Mechanics \& Engineering, vol. 27, no. 7, pp. 1387-1395, 2008.

[26] X. B. Li, F. J. Zhao, T. Feng, and X. M. Deng, "A multifunctional testing device for rock fragmentation by combining cut with impact," Tunnelling \& Underground Space Technology, vol. 19, no. 4-5, p. 526, 2004. 
[27] X. B. Li, T. Zhou, and D. Li, "Dynamic strength and fracturing behavior of single-flawed prismatic marble specimens under impact loading with a split-hopkinson pressure bar," Rock Mechanics \& Rock Engineering, vol. 50, no. 1, pp. 29-44, 2017.

[28] H. T. Li, C. X. Jiang, Y. D. Jiang, H. W. Wang, and H. B. Liu, "Mechanical behavior and mechanism analysis of coal samples based on loading rate effect," Journal of China University of Mining \& Technology, vol. 44, no. 3, pp. 430-436, 2015.

[29] S. J. Yang, Z. Sheng, and H. L. Wang, "Experimental analysis on mechanical effects of loading rates on limestone," Chinese Jounal of Geotechnical Engineering, vol. 27, no. 7, pp. 786-788, 2005.

[30] D. Huang, R. Q. Huang, and Y. X. Zhang, "Experimental investigations on static loading rate effects on mechanical properties and energy mechanism of coarse crystal grain marble under uniaxial compression," Chinese Journal of Rock Mechanics \& Engineering, vol. 31, no. 2, pp. 245-255, 2012.

[31] Y. W. Li, Y. D. Jiang, Y. M. Yang, and Z. Ma, "Research on loading rate effect of uniaxial compressive strength of coal," Journal of Mining \& Safety Engineering, vol. 33, no. 4, pp. 754-760, 2016.

[32] G. Z. Sun and Y. Sun, Principle of Rock Mass Mechanics, Science Press, Beijing, China, 2011. 


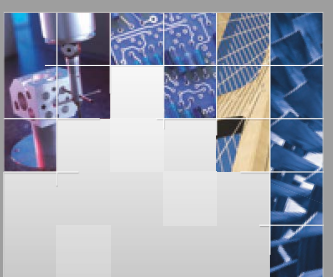

\section{Enfincering}
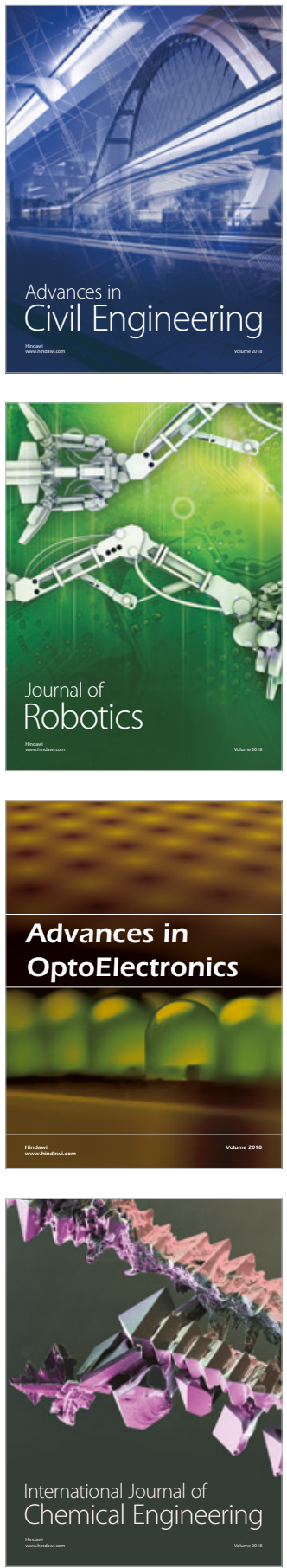

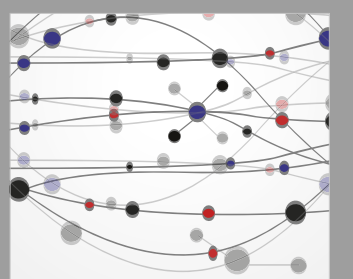

\section{Rotating \\ Machinery}

The Scientific World Journal

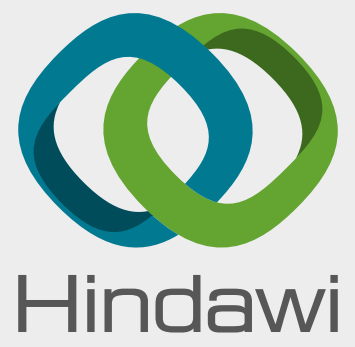

Submit your manuscripts at

www.hindawi.com
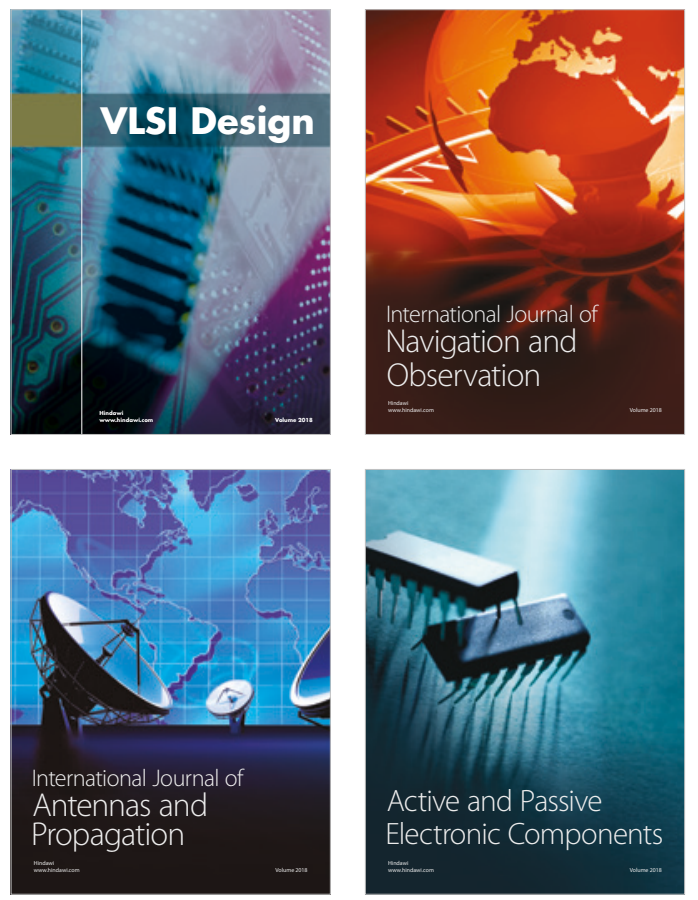
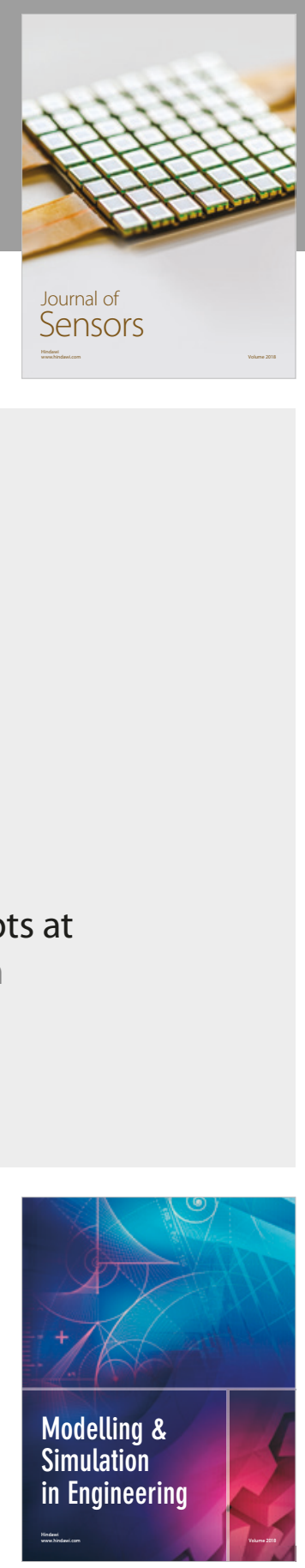

\section{Advances \\ Multimedia}
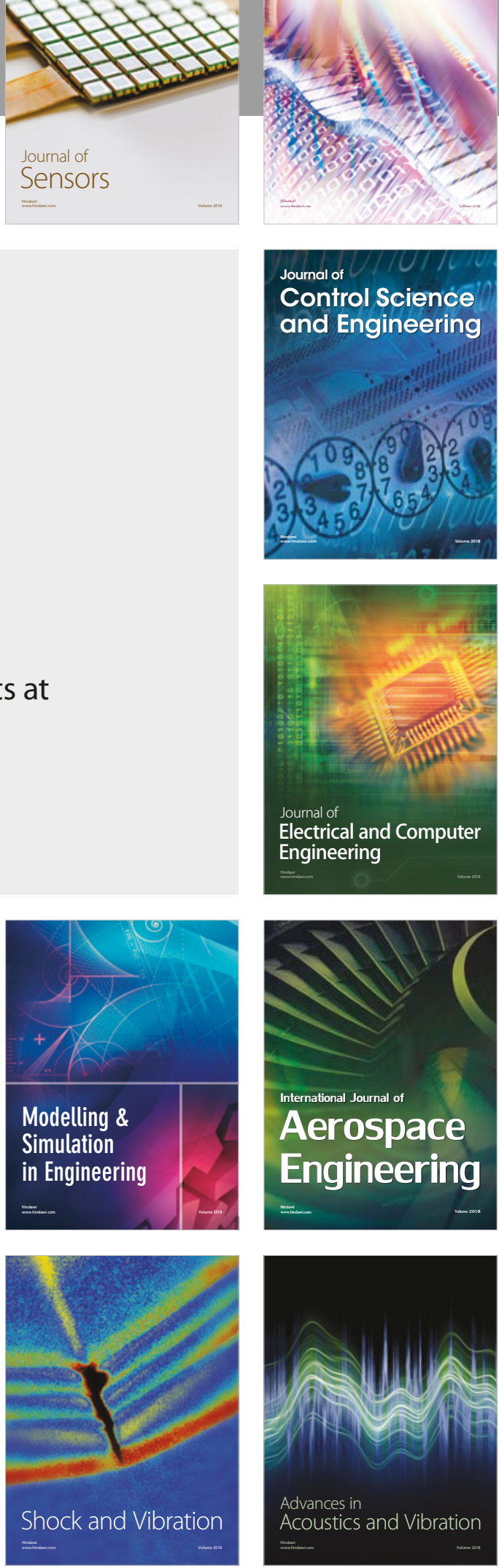